\title{
COLORAÇÃO VERDE NAS FOLHAS DA CULTURA DO ALHO VERNALIZADO EM RESPOSTA À ADUBAÇÃO NITROGENADA
}

\author{
CLARICE BACKES $\left({ }^{2 *}\right)$; CLAUDINEI PAULO DE LIMA $\left({ }^{3}\right)$; LEANDRO JOSÉ GRAVA DE GODOY $\left({ }^{4}\right)$; \\ ROBERTO LYRA VILLAS BÔAS $\left({ }^{5}\right)$; ISAO IMAIZUMI $\left({ }^{6}\right)$
}

\begin{abstract}
RESUMO
O experimento foi desenvolvido em campo com o objetivo de avaliar a viabilidade do monitoramento da adubação nitrogenada em cobertura, na cultura do alho vernalizado, por meio de medidas indiretas da intensidade de coloração verde nas folhas (medidor de clorofila SPAD), relacionando-as com o estado nutricional das plantas e com a produção de bulbos. O delineamento experimental utilizado foi o de blocos ao acaso, compreendendo seis doses de nitrogênio $\left(0 ; 20 ; 40 ; 80 ; 160 ; 320 \mathrm{~kg} \mathrm{ha}^{-1}\right)$ com cinco repetições. O N foi aplicado parceladamente em cobertura aos 20 e 75 dias após a emergência. Foram obtidos os dados de intensidade de coloração verde (ICV) e teor de $\mathrm{N}$ das folhas, massa média, produção total e classificação de bulbos, segundo o tamanho. A concentração de $\mathrm{N}$ e a ICV foram influenciadas pelas doses de N. Houve correlação significativa entre a ICV e o teor de $\mathrm{N}$ nas folhas e também entre a produção de bulbos e a ICV e entre a produção e o teor de $\mathrm{N}$. O valor máximo de ICV foi alcançado com a dose de $250 \mathrm{~kg} \mathrm{ha}^{-1}$ e a produtividade máxima e a massa média de bulbos foram obtidas na dose de $268 \mathrm{~kg} \mathrm{ha}^{-1}$ o que pela proximidade desses valores revelam que o medidor de clorofila pode ser utilizado para recomendação da adubação nitrogenada na cultura do alho. Com a dose de $237 \mathrm{~kg} \mathrm{ha}^{-1}$ de $\mathrm{N}$, obteve-se maior rendimento em $\mathrm{R} \$$.
\end{abstract}

Palavras-chave: Allium sativum L., produção de bulbos, estado nutricional

\section{ABSTRACT \\ GREEN HUE IN VERNALIZED GARLIC LEAVES IN RESPONSE TO NITROGEN FERTILIZATION}

A field experiment was carried out in order to determine the feasibility of monitoring nitrogen fertilization of vernalized garlic production by means of the correlation between the indirect measurement of the intensity of the green hue of the leaves (SPAD chlorophyll meter) and the plant nutritional condition and bulb yield. A randomized complete block design was used with six doses of nitrogen $\left(0,20,40,80,160,320 \mathrm{~kg} \mathrm{ha}^{-1}\right)$ and five repetitions. Nitrogen rates were side-dressed applied at the $20^{\text {th }}$ and the $75^{\text {th }}$ days after emergence. Data were collected for green hue intensity (GHI) and N content of leaves, average weight, total production and bulb classification as per size. Nitrogen concentrations as well as GHI were affected by N rates. Significant correlations were found between GHI and N content of leaves, between bulb production and GHI, and also between output and $\mathrm{N}$ contents. The maximum GHI value was attained a $\mathrm{N}$ rate of $250 \mathrm{~kg} \mathrm{ha}^{-1}$ and the maximum productivity and the maximum average bulb weight were attained at $268 \mathrm{~kg} \mathrm{ha}^{-1}$. Given the proximity of these rates, these results indicate that chlorophyll measurement can be used for the recommendation of nitrogen fertilization of garlic cultures. The best economic return was obtained with a $237 \mathrm{~kg} \mathrm{ha}^{-1} \mathrm{~N}$ rate.

Key words: Allium sativum L., bulb production, nutritional condition.

(1) Recebido para publicação em 23 de agosto de 2006 e aceito em 23 de novembro de 2007.

( ${ }^{2}$ ) Aluna de Doutorado do Departamento de Produção Vegetal/Horticultura, Faculdade de Ciências Agronômicas - UNESP, Caixa Postal 237, 18610-907 Botucatu (SP). E-mail: cbackes@fca.unesp.br $\left(^{*}\right)$ Autora correspondente. Bolsista CAPES.

$\left({ }^{3}\right)$ Aluno de Doutorado do Departamento de Produção Vegetal/Agricultura, Faculdade de Ciências Agronômicas - UNESP, Botucatu (SP). E-mail: cplima@fca.unesp.br

$\left({ }^{4}\right)$ Unidade Diferenciada de Registro, UNESP, Rua Tamekishi Takano, 195, 11900-000 Registro (SP). E-mail: legodoy@laser.com.br

$\left({ }^{5}\right)$ Departamento de Recursos Naturais/ Ciência do Solo, Faculdade de Ciências Agronômicas - UNESP. C.P. 237, 18.610-907, Botucatu, SP. E-mail: rlvboas@fca.unesp.br

$\left({ }^{6}\right)$ Engenheiro Agrônomo, Genove Agronegócios Ltda., Santa Juliana (MG). 


\section{INTRODUÇÃO}

No Brasil, o alho é uma das mais importantes hortaliças cultivadas, alcançando a produtividade média de 8,2 t ha ${ }^{-1}$ em 2005 (IвGE, 2005). Atualmente, apesar da área cultivada com alho ser de $10.263 \mathrm{ha}^{-1}$ (AgRiAnUAl, 2006), a produção brasileira ainda é insuficiente para suprir o mercado nacional.

A manutenção de níveis adequados de fertilidade no solo, especialmente $\mathrm{N}$, nutriente que mais contribui para o aumento da produtividade e da qualidade dos bulbos, é fator decisivo para o bom desempenho da cultura do alho (MAGALHÃES, 1986).

$\mathrm{O}$ alho é muito exigente em $\mathrm{N}$, sendo o nutriente mais extraído pela planta, em média de 1,7 a $0,85 \mathrm{~kg} \mathrm{t}^{-1}$ de alho produzido, um valor elevado quando comparado com a cultura da cebola que é de 0,09 a $0,0125 \mathrm{~kg} \mathrm{t}^{-1}$ de cebola produzida (RAIJ et al., 1997). Segundo Souza e CASAli (1986), o N influencia o número de folhas e bulbilhos, o tamanho de bulbos e a produtividade do alho. No entanto, de acordo com Filgueira (1982), o alho é extremamente sensível ao mais leve excesso no fornecimento desse nutriente.

Dentre as técnicas mais recentes com potencial para avaliar o estado nutricional de $\mathrm{N}$ da planta em tempo real, de forma rápida e de baixo custo, destacase a análise da intensidade do verde das folhas, determinada pelo uso do medidor indireto de clorofila SPAD, pelo fato de haver correlação significativa entre a intensidade do verde e o teor de clorofila com a concentração de $\mathrm{N}$ na folha. O uso do clorofilômetro tem sido estudado para diversas culturas, e com resultados satisfatórios quanto à avaliação do estado nutricional de N para as culturas de alho (VILLAS BôAs et al. 2003; LiMA, 2005), algododoeiro (NevEs et al. 2005), feijoeiro (Soratto et al. 2004; Silveira et al. 2003), milho (GodoY et al. 2007; ChAPMAN e BARRETO, 1997), batata (BoOIJ et al., 2000; Gil et al., 2002), e para a cultura de arroz (Peng et al., 1995). Entretanto, faz-se necessária sua calibração para as diferentes culturas em cada situação.

Segundo Blackmer e Schepers (1995), a vantagem da determinação da intensidade de verde em relação ao teor de $\mathrm{N}$ na folha é instantânea e não destrutiva, não sendo influenciada pelo excesso de adubação nitrogenada. Quando absorvido em excesso, o $\mathrm{N}$ acumula-se como nitrato e nesta forma, não se associa à molécula de clorofila e, portanto, não pode ser detectado pelo medidor (DWYER et al., 1995). Com o aumento das doses de $\mathrm{N}$, o teor de clorofila nas plantas atinge um valor máximo e estabiliza, sendo este ponto indicativo da dose ótima de N. Portanto, autores como BLACKMER e SCHEPERS (1995) consideram o medidor de clorofila melhor indicativo do estado nutricional de $\mathrm{N}$ na planta do que o teor foliar.
Algumas pesquisas têm demonstrado a importância do $\mathrm{N}$ no incremento da produtividade do alho, sendo as respostas às doses bastante variáveis. REZENDE e Souza (2001) verificaram que a dose de N de $149 \mathrm{~kg} \mathrm{ha}^{-1}$ foi a que proporcionou a maior produtividade total de bulbos de alho, $6.617 \mathrm{~kg} \mathrm{ha}^{-1}$. Souza e CASALI (1991) obtiveram aumento linear da produção de bulbos com doses crescentes de N (7.756 $\mathrm{t}$ com a dose de $150 \mathrm{~kg} \mathrm{ha}^{-1}$ ). Silva et al. (2000) obtiveram resposta positiva até a dose de $85 \mathrm{~kg} \mathrm{ha}^{-1}$ de $\mathrm{N}$, alcançando uma produtividade máxima de $11,95 \mathrm{t} \mathrm{ha}^{-1}$ para o cv. Gravatá, proveniente da cultura de meristemas. Ao contrário, CostA et al. (1993) não verificaram efeito significativo na produtividade total e comercial do alho quando utilizaram até $120 \mathrm{~kg} \mathrm{ha}^{-}$ ${ }^{1}$ N. LIPINSKI et al. (1995) não observaram diferença significativa na produtividade total, quando aumentaram a dose de $\mathrm{N}$ de 0 a $240 \mathrm{~kg} \mathrm{ha}^{-1}$ bem como SADARIA et al. (1997), quando aplicaram até $75 \mathrm{~kg} \mathrm{ha}^{-1}$ de N. Essa variabilidade nas respostas a aplicação de $\mathrm{N}$ se deve a diversos fatores como quantidade de matéria orgânica presente no solo, a prática ou não da adubação orgânica, ao tipo de solo utilizado, a cultura anterior e também aos níveis das doses aplicadas. Dessa forma, não pode ser padronizada uma única dose para se obter a máxima produtividade para as várias situações observadas no campo e assim, o clorofilômetro pode ser uma ferramenta para o manejo da adubação nitrogenada, podendo detectar a deficiência de $\mathrm{N}$, além de ter potencial de identificar situações onde a aplicação adicional de $\mathrm{N}$ não seja necessária.

O presente trabalho teve como objetivo avaliar o monitoramento da adubação nitrogenada em cobertura, na cultura do alho vernalizado, por meio de medidas indiretas da intensidade de coloração verde nas folhas, relacionando-as com o estado nutricional das plantas e com a produção de bulbos.

\section{MATERIAL E MÉTODOS}

O experimento foi realizado em campo no município de Santa Juliana-MG, em canteiros de 1,10 $\mathrm{m}$ de largura $\times 2,00 \mathrm{~m}$ de comprimento, com $20 \mathrm{~cm}$ de altura, em solo classificado como Latossolo VermelhoAmarelo (EMBRAPA, 1999a).

A análise de solo da camada de 0 a $20 \mathrm{~cm}$ de profundidade revelou as seguintes características, depois de ser corrigido de acordo com as necessidades da cultura: $\mathrm{K}=2,9 \mathrm{mmol}_{\mathrm{c}} \mathrm{dm}^{-3} ; \mathrm{Ca}=100 \mathrm{mmol}_{\mathrm{c}} \mathrm{dm}^{-3}$; $\mathrm{Mg}=26 \mathrm{mmol}_{\mathrm{c}} \mathrm{dm}^{-3} ; \mathrm{P}=104 \mathrm{mg} \mathrm{dm}{ }^{-3} ; \mathrm{H}+\mathrm{Al}=12$ mmol $_{\mathrm{c}} \mathrm{dm}^{-3} ; \mathrm{pH}$ em $\mathrm{CaCl}_{2}=6,3 ; \mathrm{V}=91 \%$; matéria orgânica $=30 \mathrm{~g} \mathrm{dm}^{-3}$. 
Para a adubação, aplicaram-se $600 \mathrm{~kg} \mathrm{ha}^{-1} \mathrm{de}$ superfosfato simples; $200 \mathrm{~kg} \mathrm{ha}^{-1}$ de cloreto de potássio; $10 \mathrm{~kg} \mathrm{ha}^{-1}$ de sulfato de zinco; $10 \mathrm{~kg} \mathrm{ha}^{-1} \mathrm{de}$ ácido bórico e $2.500 \mathrm{~kg} \mathrm{ha}^{-1}$ de farelo de algodão (4 dag $\mathrm{kg}^{-1}$ de N).

O plantio dos bulbilhos foi realizado em 29/4/ 05 , adotando o espaçamento de $10 \mathrm{~cm}$ entre plantas e 16 $\mathrm{cm}$ entre linhas (6 linhas por canteiro), sendo a área útil amostrada de 1 metro, totalizando 60 plantas, gerando um estande de 444.444 plantas por hectare. A irrigação foi realizada por gotejamento, variando o suprimento hídrico nas diferentes fases do ciclo da cultura.

Utilizou-se a cultivar Roxo Pérola de Caçador, e os bulbilhos sementes n. ${ }^{\circ} 3$ (com baixa infestação de vírus) submetidos ao tratamento de vernalização a $4{ }^{\circ} \mathrm{C}$, por período de 47 dias.

O delineamento experimental utilizado foi o de blocos ao acaso, compreendendo seis doses de nitrogênio $\left(0 ; 20 ; 40 ; 80 ; 160 ; 320 \mathrm{~kg} \mathrm{ha}^{-1}\right)$ com cinco repetições. $\mathrm{O} N$ foi aplicado em cobertura aos 20 e 75 dias após a emergência (DAE) sendo metade da dose aplicada antes da diferenciação e, a segunda, após a diferenciação completa, utilizando-se nitrato de amônio em ambos os casos.

Aos 70 e 100 DAE foi feita a avaliação da intensidade da coloração verde das folhas (ICV) do alho, através do medidor indireto de clorofila SPAD502 (Konica Minolta, Japão) cuja unidade é denominada SPAD, e as mesmas folhas foram coletadas para determinação da concentração de $\mathrm{N}$. Para estas avaliações utilizou-se a quinta folha (a partir da base da planta).

A colheita do experimento foi realizada aos 120 dias após o plantio, avaliando-se massa média e produção total de bulbos e a classificação dos bulbos, de acordo com a Portaria n. ${ }^{\circ} 242$, de 17 de setembro de 1992 (ЕMBRAPA, 1999b).

Calculou-se o rendimento do alho, em R\$ $\mathrm{ha}^{-1}$, levando em consideração o tamanho dos bulbos, com base em preços obtidos pela empresa Genove Agronegócios Ltda. de Santa Juliana, MG (Tabela 1).

Tabela 1. Preço médio de bulbos de alho, de acordo com o tamanho, praticado pela empresa Genove Agronegócios Ltda. de Santa Juliana, MG (média dos últimos 5 anos)

\begin{tabular}{|c|c|c|c|c|c|c|}
\hline \multirow{2}{*}{ Bulbos } & \multicolumn{5}{|c|}{ Ano } & \multirow{2}{*}{ Média } \\
\hline & 2001 & 2002 & 2003 & 2004 & 2005 & \\
\hline & \multicolumn{6}{|c|}{$\mathrm{R} \$ \mathrm{~kg}^{-1}$} \\
\hline $1-2$ & 1,80 & 2,00 & 1,00 & 2,50 & 2,50 & 1,96 \\
\hline 3 & 2,30 & 2,50 & 1,60 & 3,00 & 2,80 & 2,44 \\
\hline 4 & 2,90 & 3,00 & 2,00 & 3,60 & 3,00 & 2,90 \\
\hline 5 & 3,50 & 3,40 & 2,70 & 4,50 & 3,60 & 3,54 \\
\hline 6 & 3,70 & 3,60 & 3,00 & 4,80 & 3,70 & 3,76 \\
\hline 7 & 3,90 & 3,80 & 3,10 & 5,10 & 4,00 & 3,98 \\
\hline
\end{tabular}

Os resultados foram submetidos à análise de variância e de regressão, utilizando-se o programa SisVar v.4.2 (FERREIRA, 2003).

\section{RESULTADOS E DISCUSSÃO}

$\mathrm{O}$ teor de $\mathrm{N}$ e a ICV das folhas foram influenciados pelas doses de $\mathrm{N}$ nas duas épocas avaliadas (Figuras 1 e 2). Verifica-se que aos 70 DAE, quando havia sido aplicada apenas a metade da dose de $\mathrm{N}$, não houve um ponto de máxima, com os maiores valores do teor de $\mathrm{N}$ observados com a maior dose aplicada (Figura 1A), sugerindo que nesta fase poderia ter sido aplicada mais que a metade do $\mathrm{N}$ utilizado. Aos $100 \mathrm{DAE}$, o máximo teor de $\mathrm{N}\left(30 \mathrm{~g} \mathrm{~kg}^{-1}\right)$ foi atingido com a dose de $311 \mathrm{~kg} \mathrm{ha}^{-1}$ (Figura 1B).
Para a ICV das folhas aos 70 DAE, observase um efeito quadrático com o valor máximo de ICV para a dose de $192 \mathrm{~kg} \mathrm{ha}^{-1}$, sugerindo que a dose mais elevada, aplicada até o momento, aproxima-se do ponto de máxima (Figura 2A).

Aos $100 \mathrm{DAE}$, verificou-se índice máximo $(56,3)$ com a dose de $250 \mathrm{~kg} \mathrm{ha}^{-1}$ de N. Deve-se ressaltar, no entanto, que segundo o manual do equipamento SPAD-502 (Konica Minolta, Japão) a precisão ocorre na faixa de 0 a 50 unidades SPAD, verificando-se que o valor de 56,3 ultrapassa a faixa considerada ótima para o uso do aparelho. Portanto, quando se observa a figura 3, nota-se que os valores de correlação foram elevados $(0,91$ e significativo a $1 \%)$ mesmo com leituras alcançando valores de 60 unidades SPAD. 

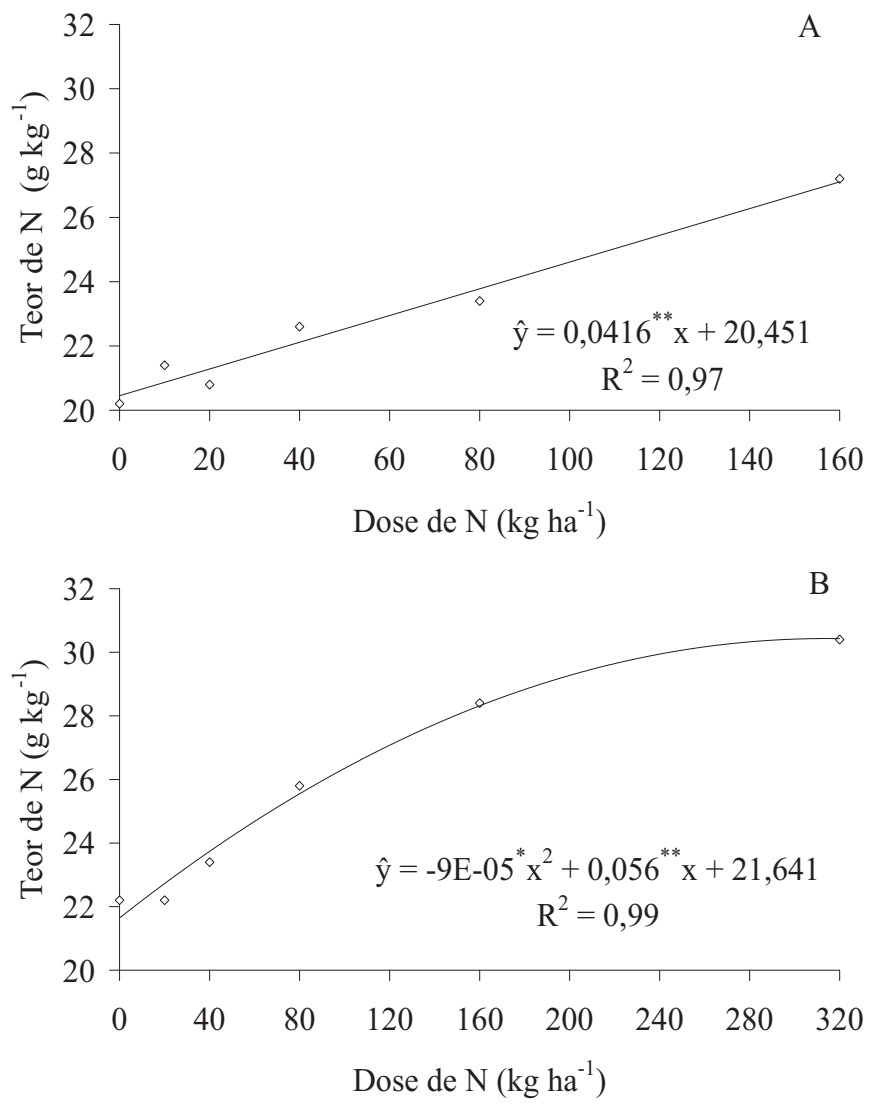

Figura 1. Teor de nitrogênio na folha de alho aos 70 (A) e 100 (B) DAE, em função de doses de N.

O máximo índice de cor observado aos 100 DAE foi atingido com uma dose abaixo da verificada na obtenção dos máximos teores de $\mathrm{N}$ nas folhas (311 $\mathrm{kg} \mathrm{ha}^{-1}$ de N). Segundo Blackmer e SChepers (1995), a medição do teor de clorofila não é influenciada pelo consumo de luxo de $\mathrm{N}$ pela planta, determinado pela análise química da folha. Lima (2005), em solo arenoso, obteve os máximos resultados de teor de $\mathrm{N}$ e intensidade de cor verde nas folhas de plantas de alho aos 100 DAE ao aplicar a dose de $360 \mathrm{~kg} \mathrm{ha}^{-1} \mathrm{de}$ $\mathrm{N}$. Observa-se que a máxima ICV foi atingida com uma dose maior quando comparada aos resultados desse experimento, talvez pelo fato de se observar no solo arenoso maiores respostas à adubação nitrogenada.

$\mathrm{Na}$ figura 3, verifica-se que houve boa correlação entre a ICV e o teor de $\mathrm{N}$ nas folhas de plantas de alho, mostrando desta forma que a técnica do uso do clorofilômetro tem potencial para avaliar o estado nutricional em relação ao $\mathrm{N}$ da planta em tempo real, de forma rápida, e a baixo custo.

LiMA (2005) obteve resposta positiva ao avaliar a correlação entre o ICV e o teor de $\mathrm{N}$ nas folhas de plantas de alho aos 70 e 100 DAE, com coeficientes
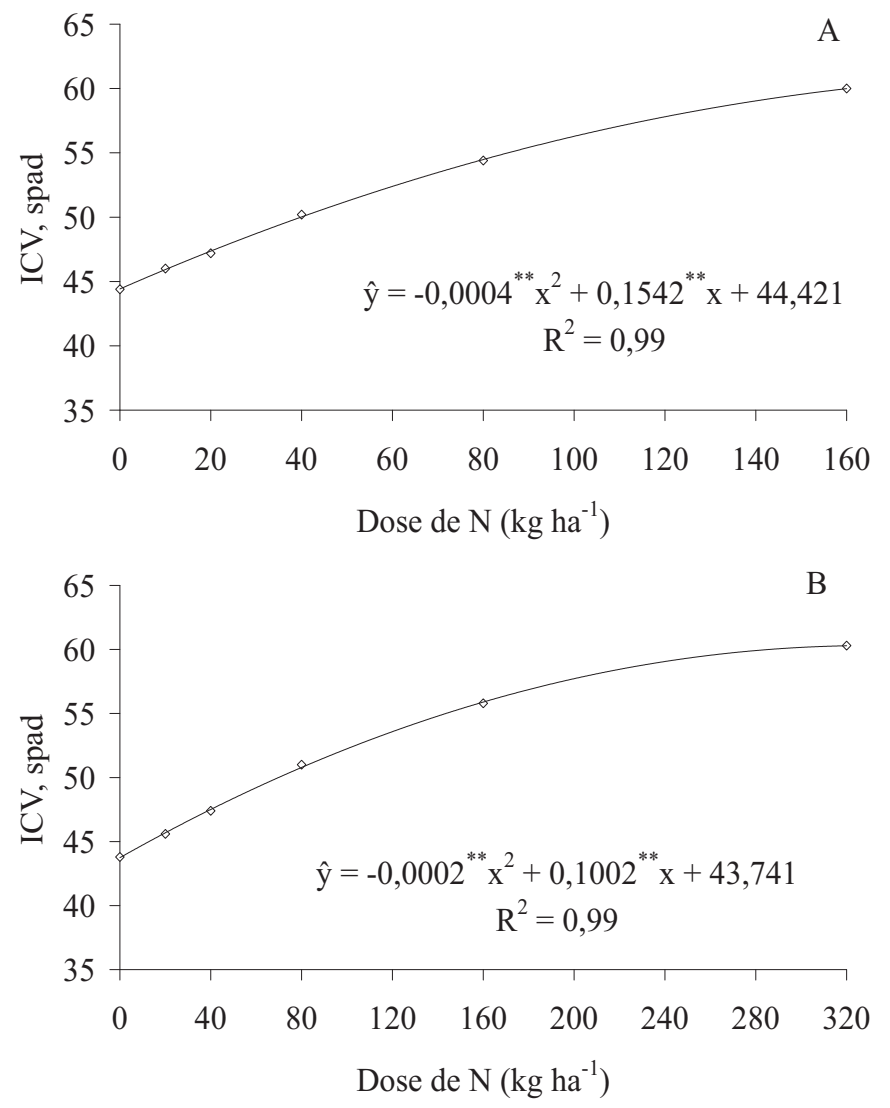

Figura 2. Intensidade de coloração verde da folha de alho aos 70 (A) e 100 DAE (B), em função de doses de N.

de 0,76 e 0,64 respectivamente e significativos a $1 \%$. VILLAS BÔAS et al. (2003) também obtiveram correlações positivas entre o teor de $\mathrm{N}$ na folha e a ICV em plantas de alho aos 85 e 122 dias após o plantio, com coeficientes de 0,53 e 0,57. Peng et al. (1995) e CHAPMAN e BARRETO (1997), para as culturas de arroz e milho, respectivamente, observaram coeficientes de correlação em torno de 0,95 , quando consideraram a massa específica da folha para reduzir o efeito de sua espessura na leitura do aparelho.

Para a massa média de bulbos (Figura 4A), houve efeito quadrático, cuja dose de $268 \mathrm{~kg} \mathrm{ha}^{-1}$ de $\mathrm{N}$ proporcionou a máxima massa média de bulbos (36 g). Souza e Casali (1991), utilizando a cv. Júreia também verificaram efeito positivo das doses de $\mathrm{N}$, porém com aumento linear na massa de bulbos, alcançando massa média em torno de $30 \mathrm{~g}$ para a dose de $180 \mathrm{~kg} \mathrm{ha}^{-1}$. Garcia et al. (1994), Resende e Souza (2001) também obtiveram aumento linear no massa média de bulbos com doses crescentes de nitrogênio $\left(21,6\right.$ e $31,94 \mathrm{~g}$ com as doses de 150 e $120 \mathrm{~kg} \mathrm{ha}^{-1}$ respectivamente). Lima (2005) não verificou diferença significativa para as diferentes doses de N (0 a 360 $\left.\mathrm{kg} \mathrm{ha}^{-1}\right)$, no entanto, utilizou além do fertilizante 
químico $20 \mathrm{t}^{\text {ha }}{ }^{-1}$ de esterco bovino contendo 1 dag $\mathrm{kg}^{-1}$ de N. Desses resultados despende-se a dificuldade de fixar uma dose de $\mathrm{N}$ e reforça a indicação do uso do clorofilômetro como forma de, através de um acompanhamento sistemático, indicar a necessidade ou não de adubação complementar de $\mathrm{N}$.
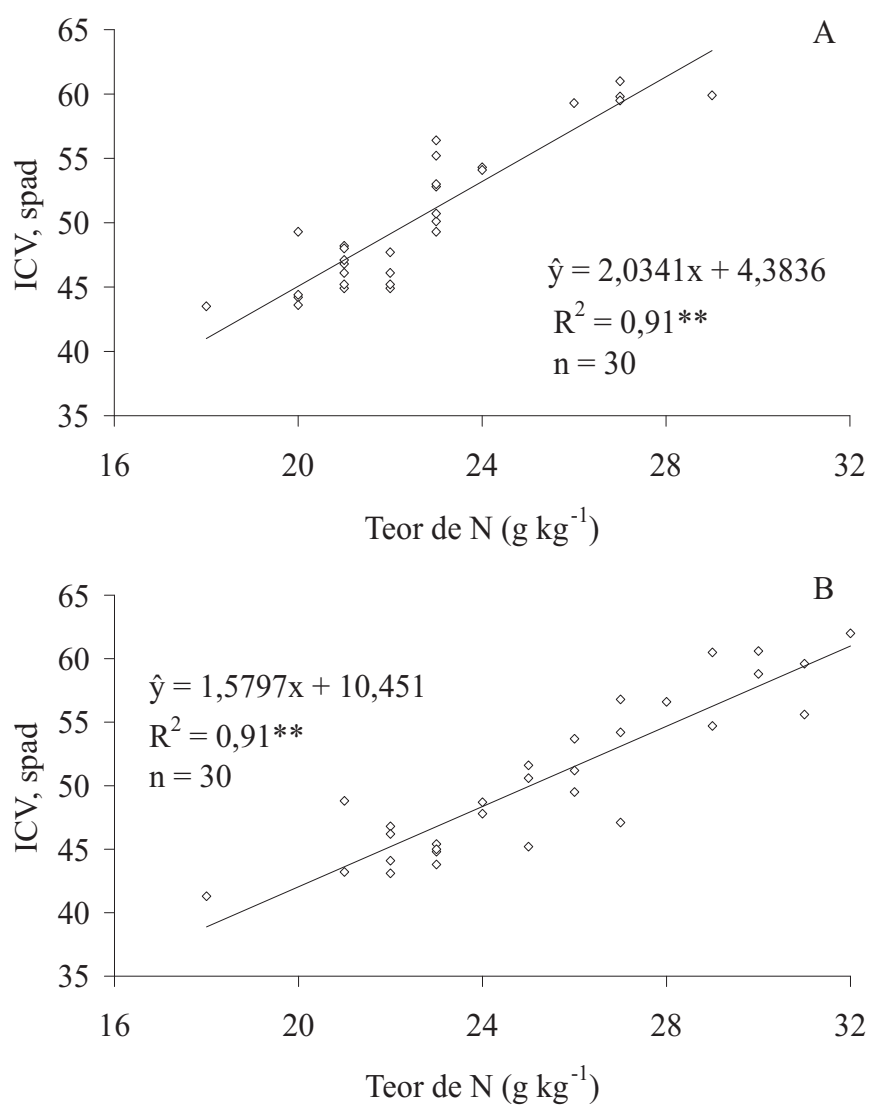

Figura 3. Correlação entre a intensidade de coloração verde (ICV) e o teor de $\mathrm{N}$ nas folhas de plantas de alho aos 70 (A) e 100 DAE (B).

Para a produção total de bulbos, observa-se que a máxima produção $\left(14,25 \mathrm{t} \mathrm{ha}^{-1}\right)$ foi alcançada com a dose de $268 \mathrm{~kg} \mathrm{ha}^{-1}$ de N (Figura 4B). Deve-se ressaltar que, além da adubação nitrogenada inorgânica, utilizaram-se para todos os tratamentos $2.500 \mathrm{~kg}$ de farelo de algodão, contendo 4 dag $\mathrm{kg}^{-1}$ de $\mathrm{N}$, o que deve ter influenciado tanto no massa média de bulbos como na produção. De forma semelhante ao observado para massa média de bulbo, para a produção de bulbos os trabalhos encontrados na literatura também são variáveis. SouZA e CASALI (1991) obtiveram aumento linear da produção de bulbos com doses crescentes de nitrogênio $\left(7,76 \mathrm{t} \mathrm{ha}^{-}\right.$ 1 até a dose de $150 \mathrm{~kg} \mathrm{ha}^{-1}$ ). Silva et al. (2000) obtiveram resposta positiva até a dose de $85 \mathrm{~kg} \mathrm{ha}^{-1}$ de $\mathrm{N}$, atingindo a produtividade máxima de $11,95 \mathrm{t}$ $\mathrm{ha}^{-1}$ para a cv. Gravatá, proveniente da cultura de meristemas. RESENDE e SOUZA (2001) verificaram que a dose de $\mathrm{N}$ de $149 \mathrm{~kg} \mathrm{ha}^{-1}$ foi a que proporcionou a máxima produtividade total de bulbos de alho, 6,62 $\mathrm{t}$ ha ${ }^{-1}$; já na produção de bulbos comerciais, verificaram máxima produção com a dose $40 \mathrm{~kg} \mathrm{ha}^{-1}$, atribuindo a diminuição para doses mais elevadas ao alto teor de matéria orgânica presente no solo $\left(30 \mathrm{~g} \mathrm{~kg}^{-1}\right)$. COSTA et al. (1993) não verificaram efeito significativo do $\mathrm{N}$ na produtividade total e comercial quando utilizaram até $120 \mathrm{~kg} \mathrm{ha}^{-1}$. LipinsKi et al. (1995) também não observaram diferenças significativas quando variaram a dose de $\mathrm{N}$ de 0 a $240 \mathrm{~kg} \mathrm{ha}^{-1}$ e SADARIA et al. (1997) quando aplicaram até $75 \mathrm{~kg} \mathrm{ha}^{-1}$. LimA (2005) verificou que a produção total de bulbos não foi influenciada pelas doses de $\mathrm{N}$ aplicadas, associando esse fato à prática da adubação orgânica realizada em todos os tratamentos $\left(20 \mathrm{t} \mathrm{ha}^{-1}\right.$ de esterco bovino contendo 1 dag $\mathrm{kg}^{-1}$ de N).

Além dos fatores citados anteriormente, como tipo de solo, nível de matéria orgânica no solo, adubação orgânica, cultura anterior e níveis das doses aplicadas, a variabilidade de respostas à adubação nitrogenada também pode ser atribuída às cultivares utilizadas.
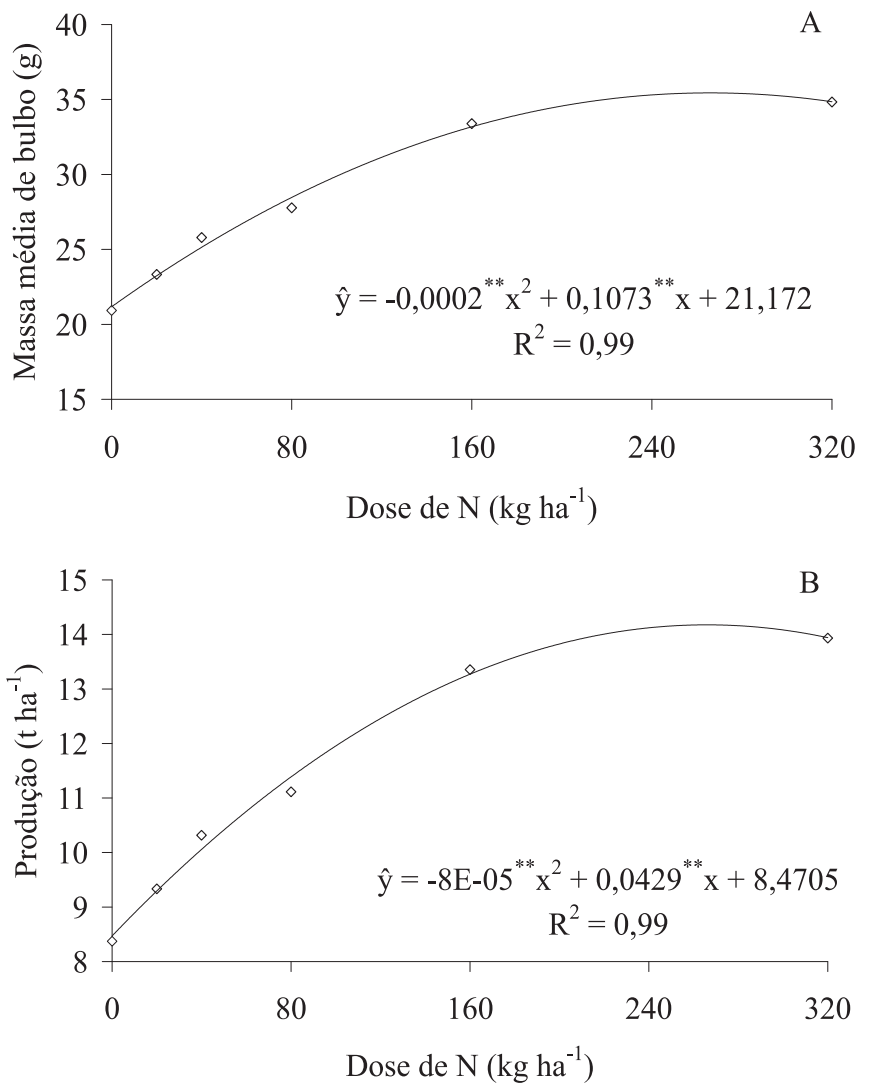

Figura 4. Massa média de bulbo (A) e produção total de bulbos de alho (B) em $\mathrm{t} \mathrm{ha}^{-1}$ em função de doses de nitrogênio. 
A produtividade observada neste experimento é considerada superior àquelas constatadas na literatura, reforçando-se o melhoramento das técnicas de produção à boa condição de manejo do experimento e também ao uso de cultivar livre da infestação de vírus, com melhores resultados.

A máxima massa média de bulbos e a máxima de produção foram alcançadas com doses superiores aos resultados verificados por outros autores. Esse resultado pode ser explicado pelo fato de que o espaçamento utilizado neste experimento foi menor $(0,10 \mathrm{~m} \times 0,16 \mathrm{~m})$, quando comparado com outros trabalhos citados, o que gerou em torno de 444.444 plantas por hectare. Com maior quantidade de plantas, maior é a absorção de nutrientes.

$\mathrm{Na}$ figura 5, verifica-se que houve correlação significativa entre a produção de bulbos e a intensidade de coloração verde das folhas $\left(R^{2}\right.$ $=0,88)$ e entre a produção de bulbos e o teor de $\mathrm{N}$ $\left(\mathrm{R}^{2}=0,87\right)$, indicando que a medida da ICV, através do clorofilômetro, pode ser boa medida para melhorar o manejo da adubação nitrogenada na cultura do alho. Gil et al. (2002) também obtiveram correlação positiva e significativa $\left(R^{2}=\right.$ $0,62)$ entre os valores do índice SPAD e os da produção de tubérculos de batata ao aplicarem doses crescentes de N.

Em avaliação feita durante o ciclo da cultura do milho, PIEKIELEK e Fox (1992) observaram que os valores SPAD na folha correlacionaram-se com a quantidade de $\mathrm{N}$ adicionada e com a produção de grãos.

Analisando a produção de bulbos, verificou-se que não houve incidência de bulbos pseudoperfilhados e nem de bulbos chochos, características que depreciam o produto e diminuem a produtividade. A produção total de bulbos de alho, classificada segundo o diâmetro transversal, ficou concentrada nas classes $3,4,5$ e 6, sendo os bulbos destas classes considerados comerciais.

Na figura 6, é possível observar que com o aumento das doses de $\mathrm{N}$ houve aumento na concentração de bulbos na classe 5 , os maiores valores foram verificados na maior dose, e uma diminuição na concentração de bulbos na classe 3 (bulbos menores) até a dose de $160 \mathrm{~kg} \mathrm{ha}^{-1}$. Com a dose de $320 \mathrm{~kg} \mathrm{ha}^{-1}$, observa-se aumento na produção de bulbos menores, os quais possuem menos valor comercial e promovem menor produção total, diminuindo o rendimento do produtor.
A maior concentração de bulbos na classe 6 foi constatada na dose de $160 \mathrm{~kg} \mathrm{ha}^{-1}$ de N. Os bulbos pertencentes a essa classe são maiores, sendo vantajoso para o produtor, considerando que os maiores preços recaem sobre os bulbos de maior tamanho. Lima (2005) não observou diferença significativa para a classificação de bulbos com o aumento das doses de $\mathrm{N}$, mesmo tendo concentração maior na classe 7 , bulbos com diâmetro maior que $>56 \mathrm{~mm}$.

A figura 7 representa a regressão dos dados de rendimento da produção de alho, em $R \$ h^{-1}$ em função das doses de $\mathrm{N}$ aplicadas. Levando-se em consideração o tamanho dos bulbos, com base em preços obtidos, verifica-se que houve maior rendimento $(\mathrm{R} \$ 45.623,98)$ com a dose de $237 \mathrm{~kg} \mathrm{ha}^{-1}$ de $\mathrm{N}$.
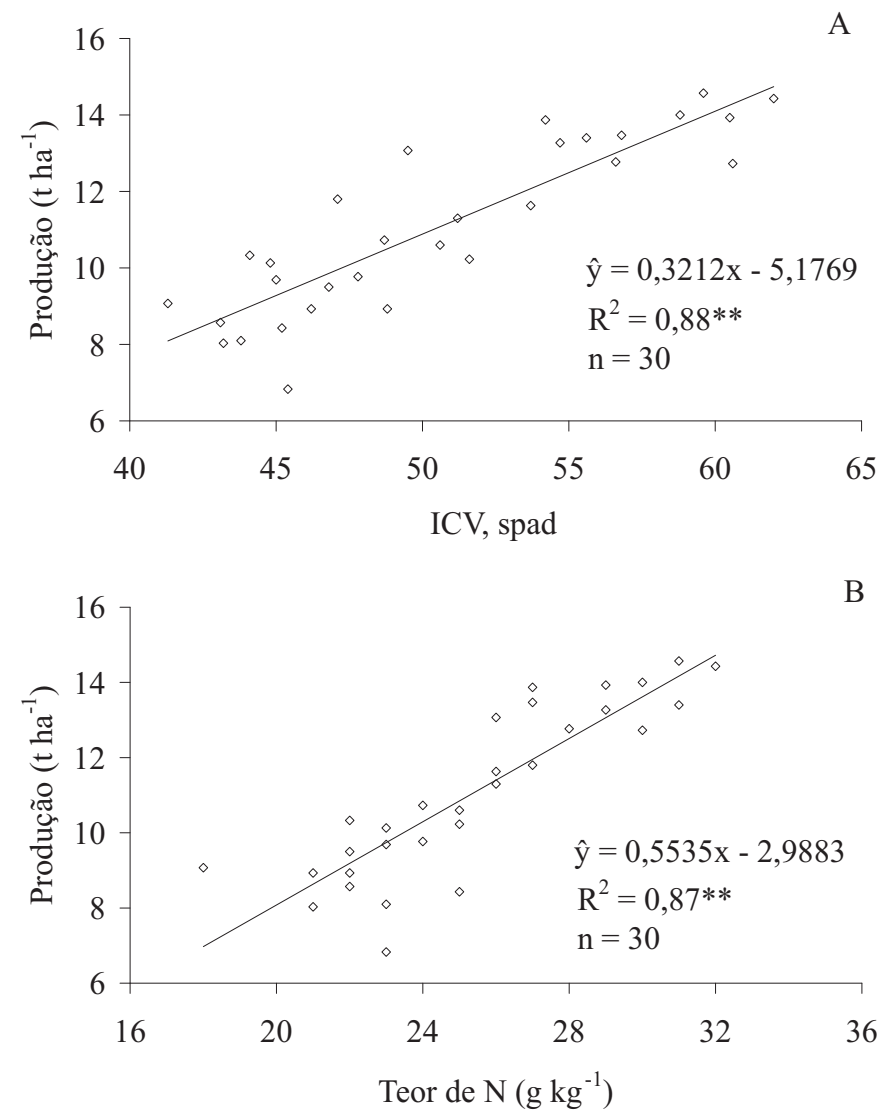

Figura 5. Correlação entre a produção de bulbos de alho e a intensidade de coloração verde (A) e o teor de $\mathrm{N}$ na folha (B). 


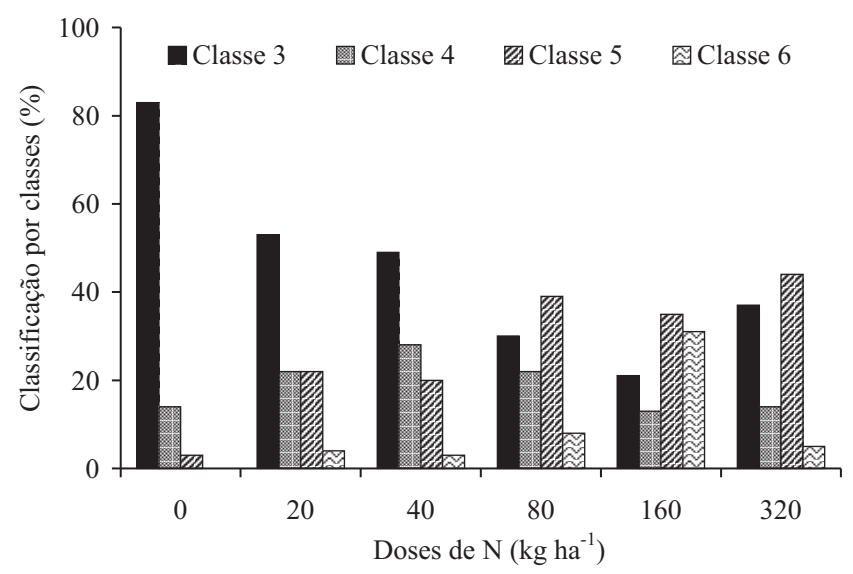

Figura 6. Classificação dos bulbos, segundo o diâmetro transversal $(\mathrm{mm})$ em porcentagem por classe (Portaria $\mathrm{n}^{\circ} 242$, de 17 de setembro de 1992). Embrapa (1999).

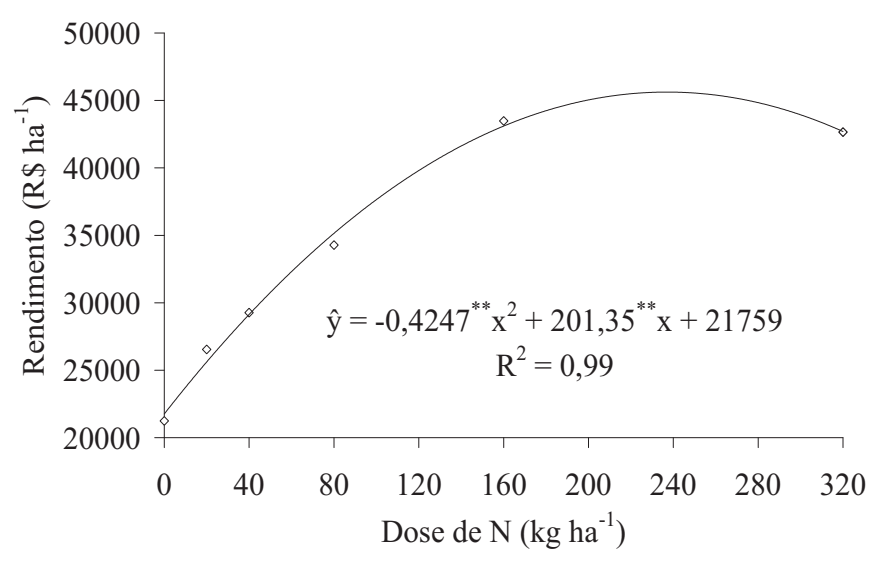

Figura 7. Rendimento da produção de alho em $\mathrm{R} \$ \mathrm{ha}^{-1}$ em função de doses de nitrogênio.

\section{CONCLUSÃO}

O valor máximo de ICV foi alcançado com a dose de $250 \mathrm{~kg} \mathrm{ha}^{-1}$ e a produtividade máxima e a massa média de bulbos foram obtidos na dose de 268 $\mathrm{kg} \mathrm{ha}^{-1} \mathrm{o}$ que pela proximidade dos valores indicam que o clorofilômetro pode ser utilizado para recomendação da adubação nitrogenada na cultura do alho.

\section{REFERÊNCIAS}

AGRIANUAL: Anuário Estatístico da Agricultura Brasileira, São Paulo, p.170-173, cultura do alho, 2006.

BLACKMER, T.M.; SCHEPERS, J.S. Use of chorophyll meter to monitor nitrogen status and schedule fertigation for corn. Journal of Production Agriculture, Madison, v.8, p.56-60, 1995.
BOOIJ, R.; VALENZUELA, J.L.; AGUILERA, C. Determination of crop nitrogen status using non-invasive methods. In: HAVERKORT, A.J.; MACKERRON, D.K.L. (Eds.). Management of nitrogen and water in potato production. The Netherlands: Wageningen Pers, 2000. p.72-82.

CHAPMAN, S.C.; BARRETO, H.J. Using a chlorophyll meter to estimate specific lef nitrogen of tropical maize during vegetative growth. Agronomy Journal, Madison, v.89, p.556$562,1997$.

COSTA, T.M.P.;SOUZA, J.R.; SILVA, A.M. Efeitos de diferentes lâminas de água e doses de nitrogênio sobre a cultura do alho (Allium sativum L.) cv. Juréia. Ciência e Prática, Lavras, v.7, n.3, p.239-246, 1993.

DWYER, L.M.; ANDERSON, A.M.; MA, B.L.;STEWART, D.W.; TOLLENAAR, M.; GREGORICH, E. Quantifying the nonlinearity in chlorophyll meter response to corn leaf nitrogen concentration. Canadian Journal of Plant Science, Ottawa, v.75, p.179-182, 1995.

EMPRESA BRASILEIRA DE PESQUISA AGROPECUÁRIA Embrapa Sistema Brasileiro de Classificação de Solos. Brasília: Embrapa Produção de Informações, 1999a. 61p.

EMPRESA BRASILEIRA DE PESQUISA AGROPECUÁRIA Embrapa Classificação de Hortaliças. Brasília: Embrapa Hortaliças, 1999b. 61p.

FERREIRA, D.F. Sisvar versão 4.2. DEX/UFLA, 2003.

FILGUEIRA, F. A. R. Manual de olericultura: cultura e comercialização das hortaliças. São Paulo: Agronômica Ceres, 1982. v.2, 357p.

GARCIA, D.C.; DETTMANN, L.A.; BARNI, V.; LOPES, S.J. Efeito de níveis de nitrogênio no rendimento de alho. Ciência Rural, Santa Maria, v.24, n.2, p.299-302, 1994.

GIL, P.T.; FONTES, P.C.R.; CECON, P.R.; FERREIRA, F.A. Índice spad para o diagnóstico do estado de nitrogênio e para o prognóstico da produtividade de batata. Horticultura Brasileira, Brasília, v.20, n.4, p.611-615, 2002.

GODOY, L.J.G; SOUTO, L.S.; FERNANDES, D.M.; VILLAS BÔAS, R.L. Uso do clorofilômetro no manejo da adubação nitrogenada para milho em sucessão a pastagem de Brachiaria decumbens. Ciência Rural, Santa Maria, v.37, n.1, p.38-44, 2007.

INSTITUTO BRASILEIRO DE GEOGRAFIA E ESTATÍSTICA IBGE. Tabela 1612 - Quantidade produzida, Valor de produção, Área plantada e Área colhida da lavoura temporária. Disponível em: http://www.sidra.ibge.gov.be/bda/tabela/ listabl.asp?c=1612 em 15 de junho de 2005.

LIMA, C.P. Medidor de clorofila na avaliação de nutrição nitrogenada na cultura do alho vernalizado. 2005. 95f. Dissertação (Mestrado em Agronomia) - Faculdade de Ciências Agronômicas-UNESP, Botucatu.

LIPINSKI, V.; GAVIOLA de HERAS, S.; FILIPPINI, M.F. Effect of irrigation, nitrogen fertilization and close size on yield and quality of coloured garlic (Allium sativum L.). Ciencia del Suelo, v.13, n.2, p.80-84, 1995. 
MAGALHÃES, J.R. Nutrição mineral do alho. Informe Agropecuário, Belo Horizonte, v.12, n.142, p.20-30, 1986.

NEVES, O.S.C.; CARVALHO, J.G.; MARTINS, F.A.D.; PÁDUA, T.R.P.; PINHO, P.J. Uso do SPAD-502 na avaliação dos teores foliares de clorofila, nitrogênio, enxofre, ferro e manganês do algodoeiro herbáceo. Pesquisa Agropecuária Brasileira, Brasília, v.40, n.5, p.517-521, 2005.

PENG, S.; GARCIA, F.V.; LAZA, R.C.; SANICO, A.L.; VISPERAS, R.M.; CASSMAN, K.G. Increased N-use efficiency using a chlorophyll meter on higt-yilding irrigated rice. Field Crops Research, v.47, p.243-252, 1995.

PIEKIELEK, W.P.; FOX, R.H. Use of a chlorophyll meter to predict sidedress nitrogen requirements for maize. Agronomy Journal, Madison, v. 84, p.59-65, 1992.

RAIJ, B.Van;CANTARELLA, H.; QUAGGIO, J.A.; FURLANI, A.M.C. Recomendação de adubação e calagem para o Estado de São Paulo. 2.ed. Campinas: Instituto agronômico/Fundação IAC, 1997. 285p.

RESENDE, G.M.; SOUZA, R.J. Doses e épocas de aplicação de nitrogênio sobre a produtividade e características comerciais de alho. Horticultura Brasileira, Brasília, v.19, n.2, p.126-129, 2001.

SADARIA, S.G.; MALAVIA, D.D.; KHANPARA, V.D.; DUDHATRA, M.G.; VYAS, M.N.; MATHUKIA, R.K. Irrigation and nutrient requirement of garlic (Allium sativum L.) under south Saurashtra region of Gujarat. Indian Journal Agricultural Sciences, New Delhi, v.67, n.9, p.402-403, 1997.
SILVA, E. C.; MACHADO, A. S. da; SOUZA, R. J. de; CALDERÓN, J. F. T. Efeito de doses de potássio (cloreto de potássio) e nitrogênio (sulfato de amônio) em alho proveniente de cultura de tecidos. Ciência Agrotecnologia, Lavras, v.24, n.4, p.917-923, 2000.

SILVEIRA, P.M.; BRAZ, A.J.B.P.; DIDONET, A.D. Chlorophyll meter to evaluate the necessity of nitrogen in dry beans. Pesquisa Agropecuária Brasileira, Brasília, v.38, n.9, p.10831087, 2003.

SORATTO, R.P.; CARVALHO, M.A.C.; ARF, O. Teor de clorofila e produtividade do feijoeiro em razão da adubação nitrogenada. Pesquisa Agropecuária Brasileira, Brasília, v.39, n.9, p.895-901, 2004

SOUZA, R. J. De; CASALI, V. W. D. Influência do nitrogênio, potássio, cycocel e paclobutrazol na cultura do alho (Allium sativum L.). Ciência e Prática, Lavras, v.15, n.1, p. 69-78, 1991.

SOUZA, R.J.; CASALI, V.W.D. Pseudoperfilhamento: uma anormalidade genético-fisiológica em alho. Informe Agropecuário, Belo Horizonte, v.12, n.142, p.36-41, 1986.

VILLAS BÔAS, R.L.; GODOY, L.J.G.; VERZIGNASSI, J.R.; KUROSAWA, C. Teor de clorofila e de nitrogênio estimados pelo clorofilômetro nas folhas de plantas de alho. Horticultura Brasileira, Brasília, v.21, n.2, p.354, 2003. 